GRASAS Y ACEITES, 63 (4),

OCTUBRE-DICIEMBRE, 475-483, 2012,

ISSN: 0017-3495

DOI: $10.3989 /$ gya. 058012

\title{
Real time continuous oxygen concentration monitoring system during malaxation for the production of Virgin Olive Oil
}

\author{
By G. Aiello ${ }^{a}$, P. Catania ${ }^{b}$, M. Enea ${ }^{a}$, G. La Scalia ${ }^{a}$, F. Pipitone ${ }^{b}$ and M. Vallone $e^{b, *}$ \\ a Dipartimento di Ingegneria Chimica, Informatica, Gestionale, Meccanica, Università di Palermo, Viale delle \\ scienze Ed. 8, 90128 Palermo, Italy \\ ${ }^{\text {b }}$ Dipartimento dei Sistemi Agro-Ambientali, Università di Palermo, Viale delle Scienze Ed. 4, 90128 Palermo, Italy \\ ${ }^{*}$ Corresponding author: mariangela.vallone@ @unipa.it
}

\section{RESUMEN}

Sistema de monitorización en continuo a tiempo real de la concentración de oxígeno durante el batido para la producción de aceite de oliva virgen.

Durante el proceso de extracción mecánica del aceite de oliva virgen ocurren importantes fenómenos físicos y transformaciones enzimáticas que influyen en la calidad del producto final. El control de los parámetros del proceso es crucial para garantizar la calidad del aceite de oliva virgen, por tanto la monitorización y el control del proceso son requisitos fundamentales en el moderno tratamiento industrial del aceite de oliva virgen. El presente trabajo propone un sistema de monitorización innovador en tiempo real dirigido a medir continuamente la concentración de oxígeno durante el proceso de batido de la pasta de aceituna para establecer una correlación con la calidad del producto final obtenido. El sistema de medida está basado en un sensor de concentración de oxígeno directamente conectado con la cámara de batido y un sistema de adquisición de datos dirigido a analizar y almacenar los valores medidos del proceso en una base de datos. Los resultados experimentales obtenidos demuestran que el uso de oxígeno durante el proceso de batido mejora unos parámetros cualitativos del aceite de oliva virgen como los ácidos grasos libres y los polifenoles totales mientras que otros (valor de peróxido y los índices espectrofotométricos) empeoran. Estos resultados son parecidos a los obtenidos usando nitrógeno, que es la técnica tradicional para evitar los conocidos procesos de oxidación estudiados por varios investigadores, lo que demuestra que la presencia de oxígeno durante el proceso de batido puede tener efectos provechosos en la calidad del aceite de oliva virgen, cuando la concentración sea debidamente controlada.

PALABRAS CLAVE: Calidad del aceite de oliva - Control del proceso - Proceso de batido - Sistema de monitorización en tiempo real.

\section{SUMMARY}

Real time continuous oxygen concentration monitoring system during malaxation for the production of Virgin Olive Oil.

During the mechanical extraction process of Virgin Olive Oil (VOO) some important physical phenomena and enzymatic transformations occur which influence the quality of the final product. The control of process parameters is crucial to ensure the quality of VOO, therefore process monitoring and control is a fundamental requirement in the modern VOO processing industry. The present work proposes an innovative Real-Time Monitoring System (RTMS) aimed at continuously measuring the oxygen concentration during the malaxation process in order to establish a correlation with the quality of the final product obtained. This monitoring system is based on an oxygen concentration sensor directly connected to the malaxation chamber and a data acquisition system to analyze and store the measured values in a process database. The experimental results obtained show that the use of oxygen during malaxation improves some qualitative parameters of VOO such as free fatty acids and total polyphenols while others (peroxide values and spectrophotometric indexes) worsen. These results are similar to those obtained by employing nitrogen, which is the traditional technique to avoid the wellknown oxidation processes studied by several researchers, thus demonstrating that the presence of oxygen during the malaxation process can have beneficial effects on the quality of VOO when its concentration is properly controlled.

KEY-WORDS: Malaxation - Olive oil quality - Process control - Real-Time Monitoring System.

\section{INTRODUCTION}

Nowadays, the global food market is driven by an increasing demand for high quality food, characterized by excellent organoleptic properties and ensuring a healthy and nutritional contribution to the consumer's diet. In addition, the attention towards health and hygiene concerns by governments and institutions has lead to strict regulations in food safety, prescribing for example, complete food chain traceability.

Virgin Olive Oil (VOO) consumption has considerably increased in recent years due to both improved marketing strategies and the results of numerous scientific studies on its extraordinary health properties (García-González et al., 2008; Luchetti, 2002; Manna et al., 2004; Rigacci et al., 2010; Visioli et al., 2002).

VOO processing can be divided into four steps: crushing the olives into a paste, paste malaxation, decanter centrifugation and vertical centrifugation. The extraction process involves not only simple 
mechanical separation of the oil from olive paste but also some chemical/physical modifications that influence the quality of the final product (Di Giovacchino et al., 2002b). During malaxation, in particular, some important physical phenomena (breaking oil-water emulsion and coalescence of oil drops, migration of olive components in the oil or aqueous phase) and enzymatic transformations (involving phenolic compounds and triglycerides) occur (Migliorini et al., 2006). The definition of the processing conditions that allow for a selective control of the enzymes is a crucial point in the oil mechanical extraction process strictly related to sensory and health quality (Angerosa et al., 2001; Servili et al., 2000). Increasing the malaxation temperature generally raises the concentration of phenols (Amirante et al., 2001; Ranalli et al., 2001) thus improving the oxidative stability. On the contrary, the content of volatile compounds decreases as temperature increases (InarejosGarcía et al., 2009; Ranalli et al., 2001). Concerning the duration of the malaxation process, it negatively influences the phenols content, while increasing the presence of oil volatiles (Di Giovacchino et al., 2002a). Durations ranging between 30 and 45 minutes, seem to achieve the best quality levels. Ranalli et al. (2003) studied the effect of kneading time on the overall quality of virgin olive oil and determined a positive effect on yields but negative consequences on the overall oil quality, because of the progressive losses in natural antioxidant phenols.

It is also well known that the extraction process influences the dissolved oxygen concentration and affects the quality of the VOO (Amirante et al., 2007; Parenti et al., 2007; Sanchez-Ortiz et al., 2008; Servili et al., 2008; Taticchi et al., 2007).

Several studies have focused on the role of enzymatic degradation activity of polyphenoloxydases and peroxidases during the mechanical extraction process, in particular concerning their inhibition, achieved by reducing the $\mathrm{O}_{2}$ level in olive paste through the introduction of an inert gas during malaxation (Servili et al., 2003a and b). Previous studies were performed using a portable oxygen analyzer which carried out discontinuous measurements (Masella et al., 2011; Parenti et al., 2007; Sánchez-Ortiz et al., 2008) but there is a lack of studies on the real time continuous oxygen monitoring inside the malaxation machine.

Modern "supervisory control and data acquisition" (SCADA) systems allow for monitoring and controlling facilities remotely, implementing either a centralized or Distributed Control System (DCS). Traditional SCADA systems are roughly constituted by a network for the interconnection of field devices, and an enterprise layer where the integration of higher level applications takes place.

Recently, the widespread Information Technology (IT) has resulted in the creation of ubiquitous technological infrastructures that make it possible to seamlessly and transparently integrate different and diverse applications. As a result of this integration, a new generation of Internet based SCADA (e-scada) systems has been developed as a flexible and scalable solution for transferring data using open Internet protocols. E-SCADA, is hence an Internetbased SCADA (also known as Web-based SCADA), which utilizes the public Internet infrastructure as a communication medium, thus facilitating the versatile supervision and control, from any part of the world, making use of the advantages of the World Wide Web.

In the development of a process monitoring and control system for the food industry, SCADA technologies must be customized to the specific needs of the processed product, taking into account that although machines used in the food industry typically implement some sensoring features for local alerting purposes, these sensors are not generally adequate for integrated monitoring and control systems. Modern state of the art sensing devices in fact implement smart functionalities to enable a cooperative management and control. Such devices are in general capable of complex local computation thus providing a high level information and allowing for multiple sensor processing by means of data fusion algorithms and complex model based techniques (Frank, 1990; Gertler, 1988; Isermann, 1993; Kinoshita et al., 1999; Richardson et al., 2006). Finally, concerning the tracking and tracing issues, SCADA systems promote the development of electronic record keeping systems, which can be employed for food traceability as long as suitable product identification technologies are implemented. For example, for liquid products such as olive oil, the implementation of flow-meter sensors during the production process is mandatory in order to link the process parameters to the product obtained.

The present work proposes an innovative Real-Time Monitoring System (RTMS) aimed at continuously measuring the oxygen concentration during the malaxation process in order to establish a correlation with the quality of the final product obtained. The measurement system is based on an oxygen concentration sensor directly connected to the malaxation chamber and a data acquisition system to analyze and store the measured values in a process database. The research involved an experimental campaign consisting of three testing conditions where different control strategies have been compared according to some quantitative indexes directly related to the quality of the VOO obtained.

\section{MATERIALS AND METHODS}

\subsection{Experimental oil mill plant}

The experimental tests were performed employing an Alfa Laval oil mill plant and a typical Sicilian olive variety, Biancolilla, manually harvested and processed within 24 hours of harvesting. The oil mill plant was operated in continuous mode; and it was equipped with an olive washing machine, a disk crusher, a single-stage malaxation machine, a 
horizontal decanter, and a vertical centrifuge. After washing, the olives were processed with a disk crusher; then the malaxation was performed in a closed system for 40 minutes at a temperature of $27^{\circ} \mathrm{C}$. The extraction was performed with a triphasic centrifugal extractor with no water addition (Catalano et al., 2003). Oil samples were collected after each test, put in $100 \mathrm{~mL}$ dark glass bottles, stored at $12^{\circ} \mathrm{C}$ and transported to the laboratory.

The malaxation machine used in the tests was the Alfa Laval Atmosphera 650 (Figure 1), featuring a stainless steel, airtight cylinder. The machine was equipped with a pair of inlet valves for gas in order to achieve a controlled or modified malaxation atmosphere by blowing nitrogen or oxygen into the headspace of the machine and a probe for olive paste temperature control. The machine has a gap over the entire inner surface of the tank where hot water is circulated in order to control the temperature of the olive paste.

A rotary double bladed reel with a spiral inside the machine does the olive paste mixing and removes it from the walls to avoid overheating. Paste loading and unloading operations are carried out by means of automatic valves.

\subsection{Real time monitoring system}

The measurement system consists of the basic parts illustrated in Figure 2. The oxygen concentration inside the malaxation machine is sampled by means of a gas extraction system which continuously circulates the gas inside the malaxation machine through a closed loop pipe where the oxygen sensor is located. The oxygen monitoring circuit thus consists of a pipeline, a gas pump, a filter and an oxygen sensor. The pump employed is the NMP $830 \mathrm{KNE}$ from knf, which is a micro-diaphragm gas pump based on an elastic diaphragm which moves up and down at its central point by means of an eccentric. The micro pump employed can be operated in a temperature range between 5 and $40^{\circ} \mathrm{C}$ ensuring a flow of approx. $1.5 \mathrm{~L} \mathrm{~min}^{-1}$ at standard temperature and pressure (STP).

As the atmosphere extracted from the malaxation machine circulates through the closed loop pipe, the oxygen sensor periodically samples the oxygen

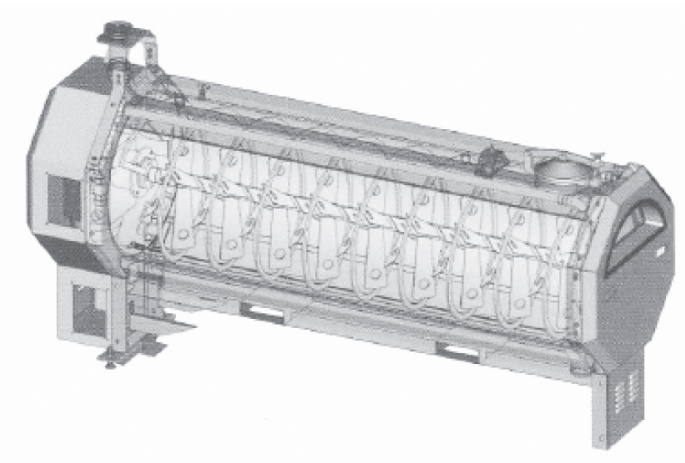

Figure 1

Scheme of the malaxation machine used in the tests. concentration. The sensor employed is the GS YUASA SK-25 which is a galvanic cell-type sensor consisting of a diffusion limited metal/air battery. The oxygen in the sample, diffusing through a barrier, is reduced to hydroxyl ions at the cathode and oxidizes a metal anode passing through the electrolyte, thus generating a current fairly proportional to the oxygen concentration. Since the rate at which oxygen reaches the cathode is limited by the diffusion barrier and the cell current is a direct function of this rate, this current is a measurement of the concentration of oxygen in the sample. For percentage measurements up to $30 \%$, a linear approximation is usually adequate, as confirmed by the output voltage curve given in Figure 3-a. In addition to galvanic cell oxygen sensors, requiring an adequate measurement time until a stable current is established, thus, in normal operating condition the measured concentration achieves $90 \%$ of its final value in approximately 15 seconds at room temperature, as depicted in Figure 3-b.

The most notable features of the sensor, as reported in Table 1, are the null influence from $\mathrm{CO}_{2}$, good linearity up to $30 \%$ oxygen, and excellent chemical durability. These features make this sensor ideal for oxygen monitoring in various applications such as the biochemical field, food industry, and domestic safety applications.

Finally, concerning the accuracy of the measurements, it must be taken into account that the oxygen sensor experiences output reduction drifts over time and needs to be calibrated at certain intervals to ensure accurate measurement. Normally oxygen sensors are calibrated using the oxygen concentration in the atmosphere (21\%) as a reference value, which may result in calibration errors if the ambient lacks oxygen or has excess oxygen, if the air pressure is substantially different from $1013 \mathrm{hPa}$ and if the air humidity and temperatures undergo rapid changes. The current generated at the oxygen sensor is then processed by a microcontroller which is an electronic device that integrates all the features required to translate an analogue signal into a digital measurement and to transmit such measurement to a computer for storage and post-processing. The use of general purpose microcontrollers for low-end digital signal processing applications has nowadays become commonplace with the availability of high speed processors. Since most signal processing systems consist of a host processor and dedicated DSP chip, the use of a single microcontroller to perform both these functions provides a simple and low cost solution. The microcontroller implemented in the system developed is the PIC16f877 which is a programmable interface controller belonging to the family of Harvard architecture programmable interface controller (PIC) made by Microchip technology, featuring a built-in $A / D$ (analog to digital) and D/A (digital to analog) converter. PICs microcontrollers are popular for process monitoring and control purposes (Chaboot et al., 2005; Tunlasakun et al., 2004), allowing the signal to be processed through a complex measuring pipeline. The input 


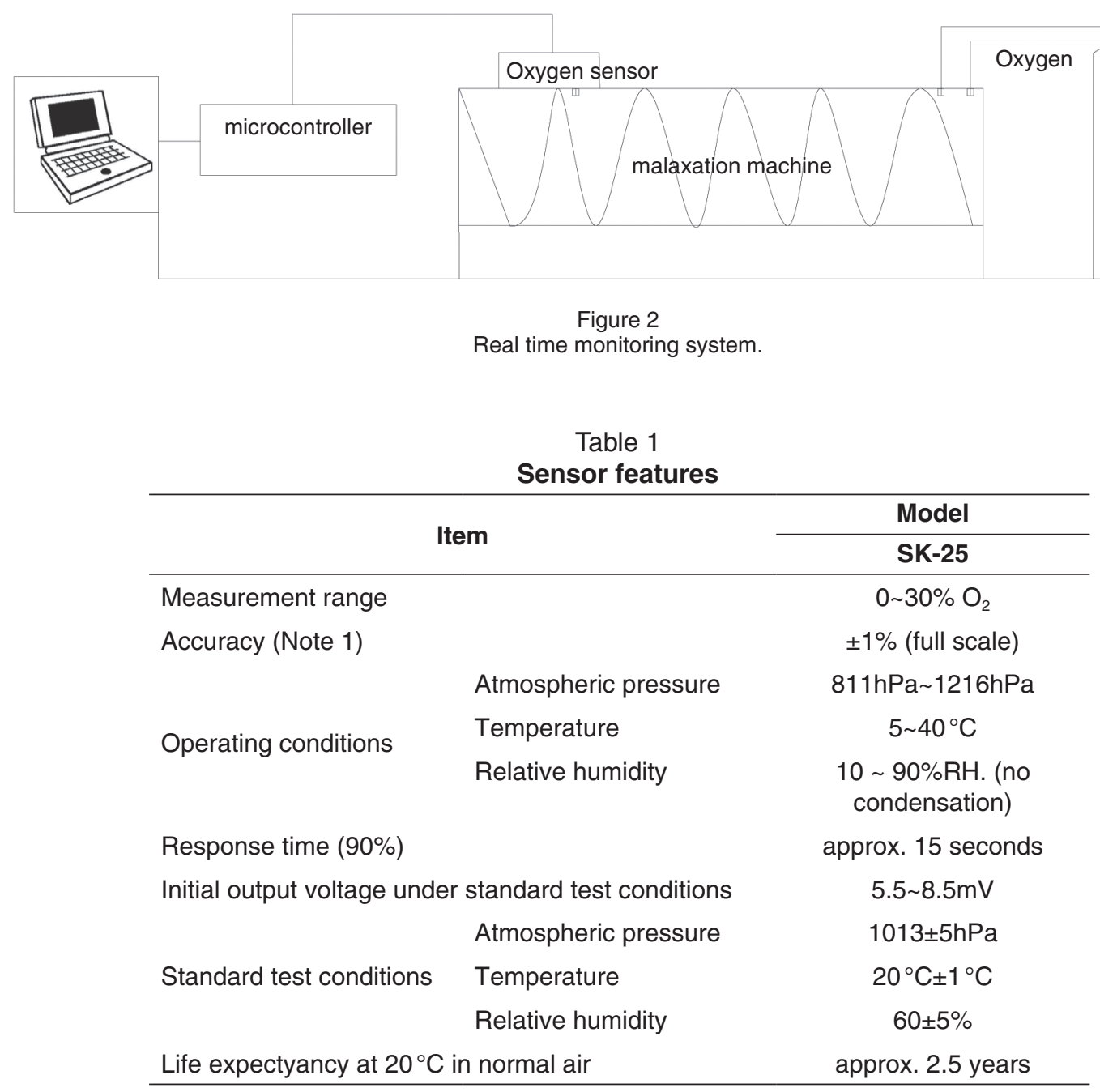

signal in fact is first passed through an input filter whose function is to band limit the signal and prevent aliasing, then it is digitized by the A/D converter at a rate determined by the sample clock to produce the discrete-time input sequence. Finally the microcontroller will communicate with the computer through universal synchronous/asynchronous receive/transmit (USART) peripheral modules, such as a Serial Communications Interface $(\mathrm{SCl})$. The following Figure 4 shows the sensor housing (a), involving the sensor itself, the pump and the power supply and the PIC Microcontroller circuit board (b).

The serial interface is connected to a computer using the RS232 communication protocol, thus serving as a full-duplex asynchronous communication between the microcontroller and the personal computer. Digitized data are then forwarded to a signal concentrator which synthesizes the additional signals originated by other sensors in the SCADA field network into a unique data stream.

The oxygen concentration data are thus buffered and transmitted to a central host for data storage and post-processing purposes. The central host will perform data Quality Assurance (QA) and Quality Control (QC) standardized procedures including threshold, persistence, and regression tests. Additionally, the central host will provide all the required services for on-site process monitoring and for web based client/server service providing. In this topology, the process control network supports both control-level applications as well as device-level applications, capable of communicating by means of wireless transmitters with $\mathrm{Wi}-\mathrm{Fi}$ devices. This feature is achieved by means of an integrated multi-functional 802.11 mesh network supporting handheld devices, including wireless transmitters, PDA, Mobile HMI, and other 3rd-party devices. The wireless network is thus an extension of the process control network which relies on W-VLAN technology.

\subsection{Experimental tests}

The experimental campaign consisted of performing the malaxation process in three different test configurations. In particular, the atmosphere inside the malaxation machine was modified by blowing oxygen and nitrogen into the mixing chamber at specific stages of the process. The consequent quality of the VOO obtained was then evaluated according to a set 


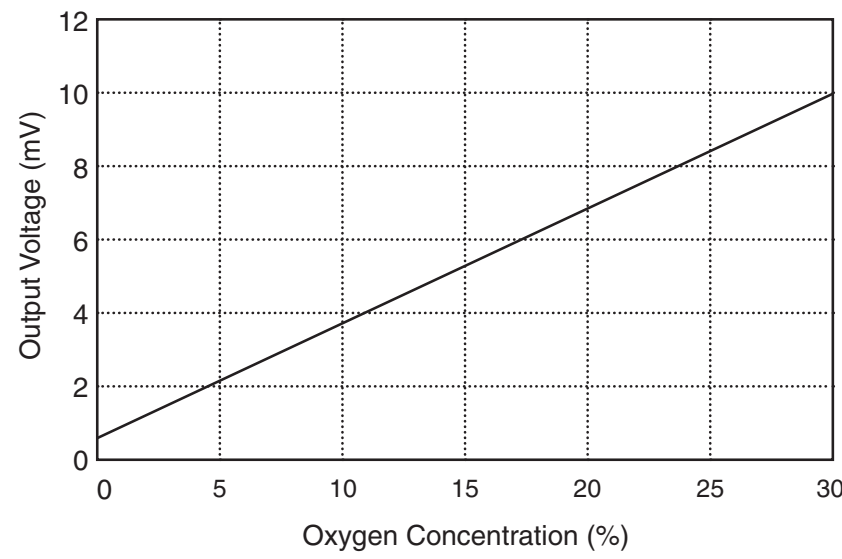

(a)

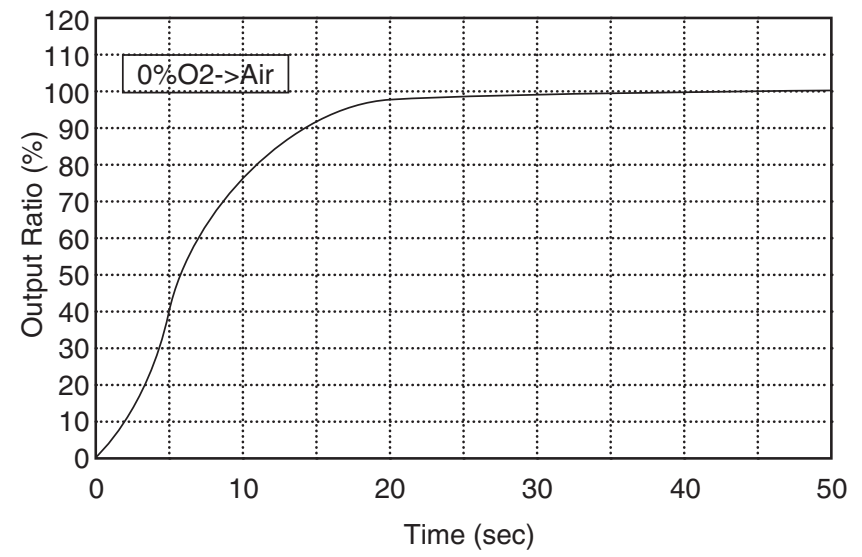

(b)

Figure 3

Output voltage curve (a). Output ratio vs. time (b).

of indicators. The following test configurations were performed:

- test T1 (control): malaxation in un-modified atmosphere;

- test T2 (in oxygen-free atmosphere): the malaxation machine is filled with nitrogen before olive paste entry;

- test T3 (in oxygen enriched atmosphere): an additional oxygen content is introduced during the malaxation process.

In all the tests the malaxation machine filling lasted 10 minutes; in test T3 the atmosphere of the malaxation chamber was saturated with oxygen by introducing $8 \mathrm{~L} \mathrm{~min}^{-1}$ of pure oxygen for 1.5 minutes at half the duration of the process (20 minutes). The dissolved oxygen measurements in the malaxation machine were performed every 30 seconds. Each test configuration was repeated three times.

\subsection{Analytical determinations on Virgin Olive Oil}

The quality of the VOO obtained from the experimental process has been evaluated taking into account the Free fatty acid (FFA) content (as oleic acid percent), the peroxide value (PV, meq $\mathrm{O}_{2}$ $\mathrm{kg}^{-1}$ ) and the spectrophotometric indexes $\mathrm{K}_{232}$ and $\mathrm{K}_{270}$, according to the official methods established by the International Olive Oil Council (IOOC, 2001) and the EEC (EC, 1991; EC 2003; EC, 2007).

The total polyphenols were spectrophotometrically estimated according to the Folin-Ciocalteu method since they are known to have a significant effect on the stability and sensory characteristics of VOO. Due to such properties, there have been proposals to include phenols in the olive oil standard for quality assessment (Blekas et al., 2002; Psomiadou et al., 2003; Ranalli et al., 1999). Polyphenols are antioxidant and represent a valuable factor for olive oil which is the only vegetable fat to be rich of such compounds. They contribute to the characteristic fruity aroma and spicy and bitter taste of VOO. For these reasons, determining the quantity and quality of the polyphenolic content is one of the most significant for quality assessment.

\subsection{Statistical Analysis}

Each laboratory test on oils was carried out in three replicates. Data were analyzed using analysis of variance and Tukey's test at the $95.0 \%$ confidence level, carried out by means of Statgraphics centurion (Statpoint inc., USA, 2005) software package.

\section{RESULTS AND DISCUSSION}

The experimental real-time monitoring system allowed for an estimation of the oxygen concentration in the headspace of the malaxation machine by means of a direct measurement of the samples extracted at each 30 seconds. Figure 5 shows the evolution of the oxygen concentration inside the malaxation machine from paste entry to discharge in the three tests.

In test T1 the oxygen concentration is $15 \%$ during the period of the olive paste entry (10 minutes). Then, as malaxation starts, the concentration decreases to approx. $0 \%$ after 30 minutes, and in the last 10 minutes (25\% of the total duration of the process), malaxation is carried out in the absence of oxygen. In test T2, where the process is performed with an oxygen concentration lower than T1, the curve shows a downward trend since the entry of olive paste, reaching $0 \%$ approximately after 20 minutes from the beginning of malaxation. In the last 20 minutes (50\% of the total operation time) malaxation is performed in the absence of oxygen. In test T3 the atmosphere composition follows the control test (T1) for 30 minutes, then as the oxygen is introduced inside the malaxation chamber, its concentration rises to approx. $20 \%$. Oxygen was introduced in order to support the lipoxygenase enzyme activity capable of synthesizing the compounds characterizing the typical vOO flavor. 

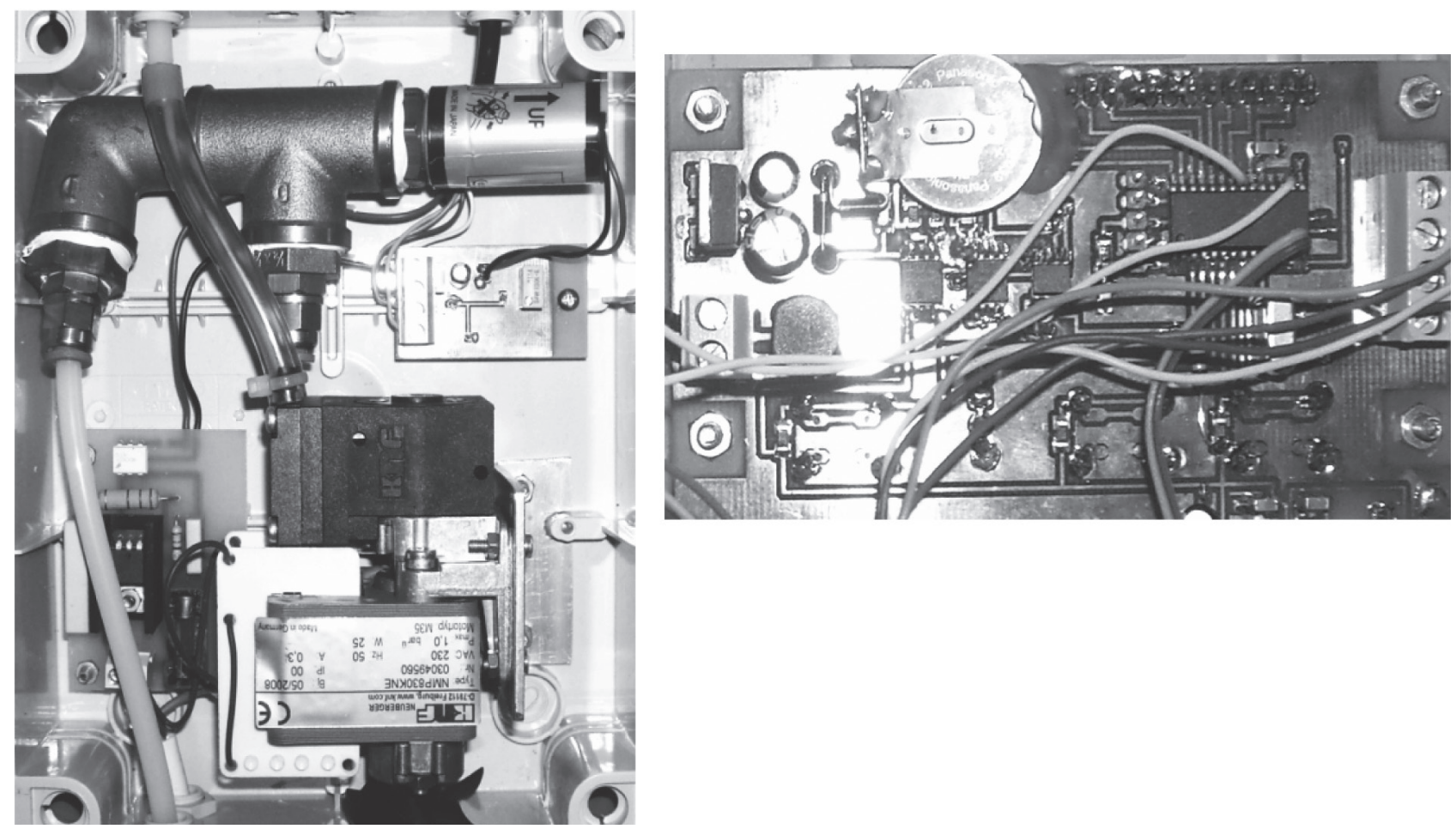

Figure 4

The sensor housing (a). The PIC Microcontroller circuit board (b).

The results of the chemical analyses of oil samples taken immediately after the end of the whole malaxation process for each test show that the lowest FFA value, equal to 0.27 , was obtained in T2, while the highest was 0.39 obtained in T1. From the comparison between the mean acidity values of the three tests (Fig.6), statistically significant differences emerge between tests T1-T2 (T2 is 31\% lower than T1) and T1-T3 (T3 is about 21\% lower than T1). It follows that by introducing gas into the malaxation machine (nitrogen or oxygen) the olive oil shows a lower FFA value than the control, and thus improves the quality of the oil.

The lowest peroxide number value, equal to 4.29 , was recorded in test $\mathrm{T} 1$, while the highest, equal to 6.37, was recorded in test T3 where oxygen was introduced. Statistically significant differences emerge between T1-T2 and T1-T3. Note that the PV increased by approximately $31 \%$ in $\mathrm{T} 2$ and $33 \%$ in T3 compared to the control test (T1). The $\mathrm{PV}$ value in T3 is to be attributed to the fact that oxygen is present within the malaxation machine for the entire process. No statistically significant differences were obtained between the tests where the normal atmosphere of the machine was modified by introducing nitrogen or oxygen (fig.6). It follows that the introduction of oxygen in the middle of the malaxation process does not worsen the PV in the final product compared to the test performed in an oxygen-free atmosphere.

Concerning $\mathrm{K}_{232}$, the highest value was obtained in test T3, equal to 1.795. From the comparison among $\mathrm{K}_{232}$ mean values of the three tests, statistically significant differences emerge between T1-T3 (T3 is $19 \%$ higher than T2) and T2-T3 (T2 is about $14 \%$ lower than T3) (Fig.6). This suggests that the best results in terms of quality are obtained both in the control test and in test T2. This means that the presence of oxygen is not particularly favorable towards $\mathrm{K}_{232}$.

Concerning $\mathrm{K}_{270}$, the results were approximately the same as for $\mathrm{K}_{232}$. Statistically significant differences were found between T1 and T3 with T1 about 27\% lower than T3 and between T2 and T3 with T2 about $35 \%$ lower than T3. As above, the presence of oxygen increased $\mathrm{K}_{270}$ values.

Total polyphenols showed the highest value in T2 (equal to 176.35) and the lowest in T1 (equal to

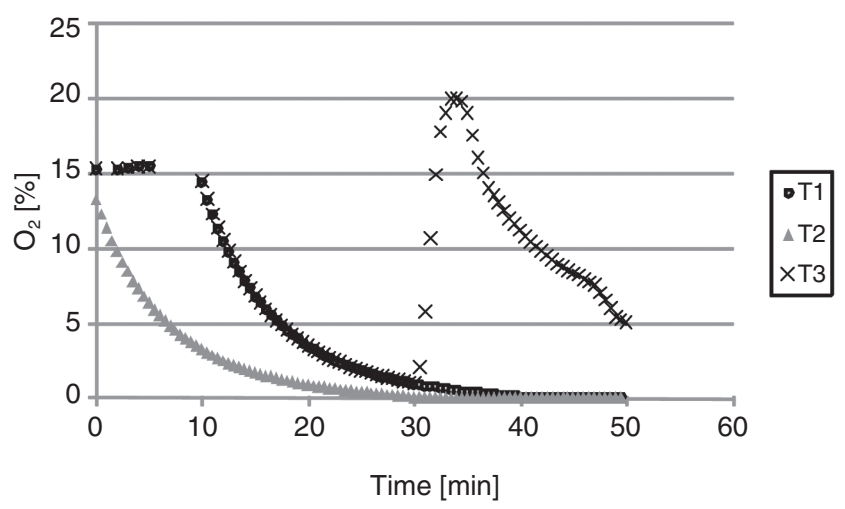

Figure 5

Evolution of the oxygen concentration inside the malaxation machine during olive paste processing in the three tests T1, T2 and T3 in terms of mean values of three replicates. 

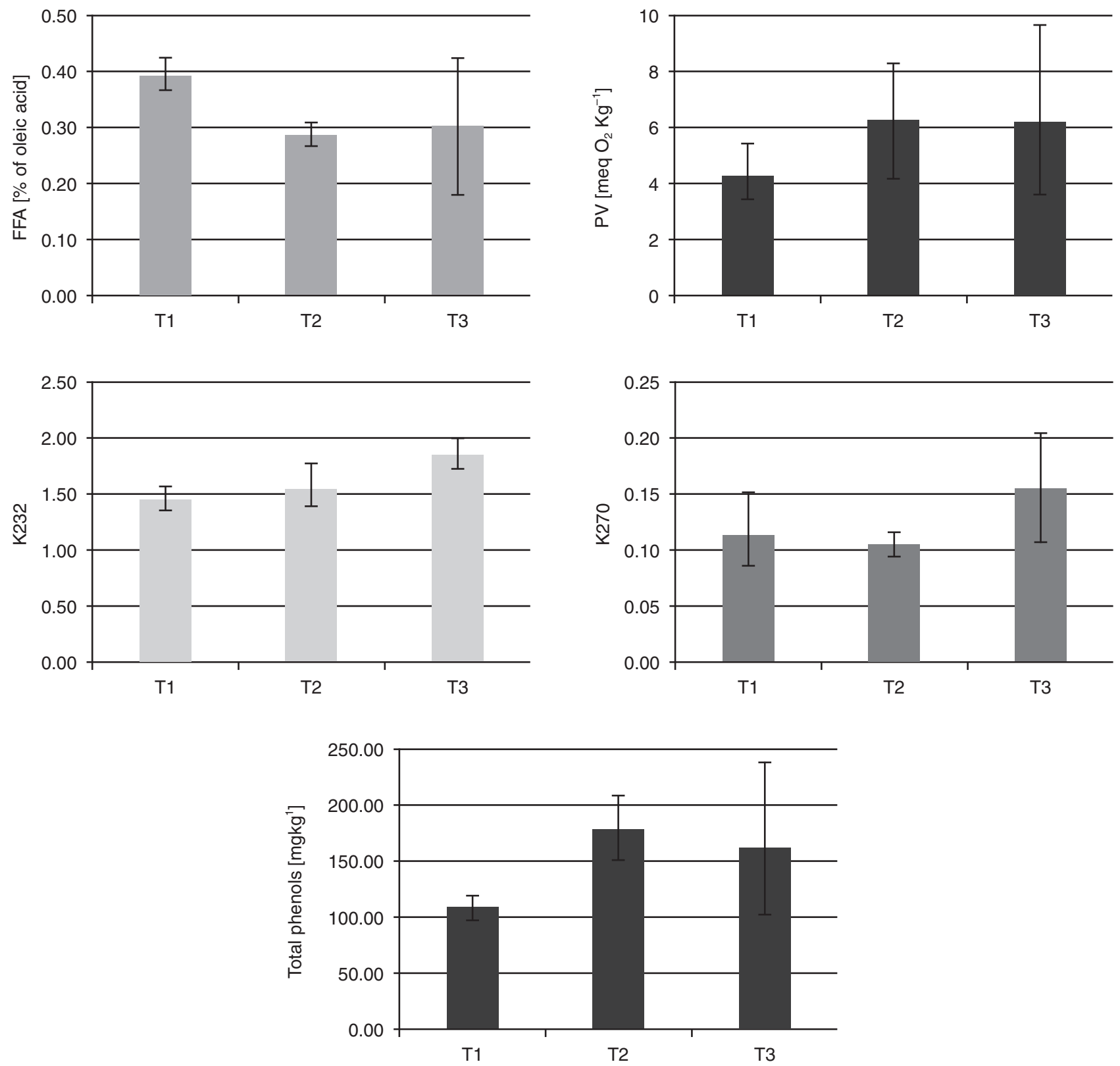

Figure 6

Free fatty acid (FFA) content (as oleic acid percent), peroxide value $\mathrm{PV}\left(\mathrm{meq} \mathrm{O}_{2} \mathrm{~kg}^{-1}\right.$ ), spectrophotometric indexes $\mathrm{K}_{232}$ and $\mathrm{K}_{270}$ and total phenols $\left(\mathrm{mg} \mathrm{kg}^{-1}\right)$ in T1, T2 and T3. Data are reported as means \pm standard deviations of the three replicates (Tukey's test at the $95 \%$ confidence level).

111.97). Statistically significant differences were found between T1-T2 and T1-T3; the control test $\mathrm{T} 1$ was about $37 \%$ lower than T2 and about $34 \%$ lower than T3 (Fig.6). It follows that the oxygen addition in the middle stage of malaxation and nitrogen addition in the initial stage improve the final content of polyphenols in the oil.

The results obtained from the experimental tests suggest that the introduction and continuous monitoring of oxygen inside the malaxation machine modify the basic analytical parameters of VOO. In particular, while some of these are positively affected as total polyphenols and free fatty acids, others, such as PV and spectrophotometric indexes, worsen.
However, considering that the increase in polyphenols leads to a higher stability of the oil during storage, this could counteract the increase in peroxide value and spectrophotometric indexes.

\section{CONCLUSIONS}

This paper reports the first results from an innovative malaxation process in controlled atmosphere involving a real time process monitoring and control system which allows for obtaining a desired concentration of oxygen in the malaxation chamber. The aim of the study is to establish a correlation between the 
processing conditions and the final quality of the product obtained evaluated by means of a set of referenced indicators. While this subject has been addressed by current researches, to the best of the authors' knowledge, there is no similar approach reported in the literature.

The results obtained show that the use of oxygen during malaxation improved some qualitative parameters of VOO such as free fatty acids and total polyphenols, while others (peroxide values and spectrophotometric indexes) worsen. These results are similar to those obtained by employing nitrogen, which is the traditional technique for avoiding oxidation processes.

The research confirms the importance of continuously monitoring and controlling the oxygen concentration inside the malaxation machine for improving the quality of virgin olive oil. This is because the presence of oxygen in known concentrations could contribute to further improving VOO quality together with other important factors such as olive variety, crop management, stage of ripeness and processing parameters in the VOO extraction process.

The results obtained by means of the system proposed suggest new research scenarios for example concerning the establishment of optimal process parameters of malaxation machines, in order to improve both the quality and yield of the VOO produced.

\section{REFERENCES}

Amirante $P$, Baccioni L, Pipitone F, Catania $P$, Didonna G, Marzano F. 2007. Estrazione dell'olio di Pantelleria: un esempio di tutela paesaggistica a salvaguardia di un patrimonio storico e culturale. In: Atti del Convegno Nazionale AllA 2007: Tecnologie innovative nelle filiere: orticola, vitivinicola e olivicoloolearia, Vol. III, 33-36, Pisa e Volterra, Italy, 5-7 September.

Amirante R, Cini E, Montel GL, Pasqualone A. 2001. Influence of mixing and extraction parameters on virgin olive oil quality. Grasas Aceites 52, 198-201.

Angerosa F, Mostallino R, Basti C, Vito R. 2001. Influence of malaxation temperature and time on the quality of virgin olive oils. Food Chem. 72, 19-28.

Blekas G, Psomiadou E, Tsimidou M, Boskou D. 2002. On the importance of total polar phenols to monitor the stability of Greek virgin olive oil. Eur. J. Lipid Sci. Tech. 104, 6, 340-346.

Catalano P, Pipitone F, Calafatello AR, Leone A. 2003. Productive efficiency of decanters with short and variable dynamic pressure cones. Biosyst. Eng. 86, 459-464.

Chaboot E, McCluskey J, Wu J, Sun Y. 2005. Microcontroller-Based Artificial Synapse. Proceedings of the IEEE 31st Annual Northeast in Bioengineering Conference, 30-31.

Di Giovacchino L, Costantini N, Ferrante ML, Serraiocco A. 2002a. Influence of malaxation time of olive paste on oil extraction yields and chimica and organoleptic characteristics of virgin olive oil obtained by a centrifugal decanter at water saving. Grasas Aceites 53, 179-186.
Di Giovacchino L, Sestili S, Di Vincenzo D. 2002b. Influence of olive processing on virgin olive oil quality. Eur. J. Lipid Sci. Tech. 104, 587-601.

EC (1991). Commission regulation (EEC) no. 2568/91 of 11 July 1991 on the characteristics of olive oil and olive-residue oil and on the relevant methods of analysis. Official Journal L, 248 (0001-0083).

European Commission Regulation. EEC/1989/2003 of 6 November 2003 amending Regulation (EEC) No. 2568/91 on the Characteristics of olive oil and olivepomace oil and on the relevant methods of analysis. Off. J. Eur. Communities 2003, L295, 57-77.

European Commission Regulation. EEC/702/2007 of 21 June 2007 amending Commission Regulation (EEC) No $2568 / 91$ on the characteristics of olive oil and olive residue oil and on the relevant methods of analysis. Off. J. Eur. Union 2007, L161, 11-27.

Frank PM. 1990. Fault diagnosis in dynamic systems using analytical and knowledge-based redundancy-a survey and some new result. Automatica 26, 450472.

García-González DL, Aparicio-Ruiz R, Aparicio R. 2008. Virgin olive oil chemical implications on quality and health. Eur. J. Lipid Sci. Tech. 110, 602-607.

Gertler JJ. 1988. Survey of model-based failure detection and isolation in complex plants. IEEE Control Syst Mag, 8, 3-11.

Inarejos-García AM, Gómez-Rico A, Desamparados MS, Fregapane G. 2009. Influence of malaxation conditions on virgin olive oil yield, overall quality and composition. Eur. Food Res. Tech. 228, 671-677.

IOOC Trade standard applying to olive oil and olivepomace oil. In COI/ T.15/NC no. 2/Rev. 10; 2001.

Isermann R. 1993. Fault diagnosis of machines via parameter estimation and knowledge processingtutorial paper. Automatica 29, 815-835.

Kinoshita G, Ikhsan Y, Osumi H. 1999. Object location based on sensor fusion of visual and tactual sensing. Adv. Robot 13, 633-646.

Luchetti F. 2002. Importance and future of olive oil in the world market - an introduction to olive oil. Eur. J. Lipid Sci.Tech. 104, 559-563.

Manna C, Migliardi V, Golino P, Scognamiglio A, Galletti P, Chiariello M, Zappia V. 2004. Oleuropein prevents oxidative myocardial injury induced by ischemia and reperfusion. J. Nutr. Biochem. 15, 461-466.

Masella P, Parenti A, Spugnoli P, Calamai L. 2011. Malaxation of olive paste under sealed conditions. J. Am. Oil Chem. Soc. 88, 871-875.

Migliorini M, Mugelli M, Cherubini C, Viti $\mathrm{P}$, Zanoni B. 2006. Influence of $\mathrm{O}_{2}$ on the quality of virgin olive oil during malaxation. J. Sci. Food Agr. 86, 2140-2146.

Parenti A, Spugnoli P, Masella P, Calamai L. 2007. Influence of the extraction process on dissolved oxygen in olive oil. Eur. J. Lipid Sci. Tech. 109, 11801185.

Psomiadou E, Konstantinos X, Blekas K G, Tsimidou M Z, Boskou D. 2003. Proposed parameters for monitoring quality of virgin olive oil (Koroneiki cv). Eur. J. Lipid Sci. Tech. 105, 403-409.

Ranalli A, Contento S, Schiavone C, Simone N. 2001. Malaxing temperature affects volatile and phenol composition as well as others analytical features of virgin olive oil. Eur. J. Lipid Sci. Tech. 103, 228-238.

Ranalli A, Ferrante M L, De Mattia G, Costantini N. 1999. Analytical evaluation of virgin olive oil of first and second extraction. J. Agric. Food Chem. 47, 417-424.

Ranalli A, Pollastri L, Contento S, Lannucci E, Lucera L. 2003. Effect of olive paste kneading process time on 
the overall quality of virgin olive oil. Eur. J. Lipid Sci. Tech. 105, 57-67.

Richardson K, Petrosyan Z, Abbott R, Scott D, Hajianpour M, Ghantiwala S, Marabyan K, Quan A, Crawford R, Nystrom D. 2006. in Spacelift Telemetry Acquisition and Reporting System (STARS) Limit Checking System, Aerospace Conference, IEEE, 4-11 March 2006, pp. 8.

Rigacci S, Guidotti V, Bucciantini M, Parri M, Nediani C, Cerbai E, Stefani M, Andrea Berti A. 2010 Oleuropein aglycon prevents cytotoxic amyloid aggregation of human amylin. J. Nutr. Biochem. 21, 726-735.

Sánchez-Ortiz A, Romero C, Perez AG, Sanz C. 2008. Oxygen concentration affects volatile compound biosynthesis during virgin olive oil production. $J$. Agric. Food Chem. 56, 4681-4685.

Servili M, Baldioli M, Begliomini AL, Selvaggini R, Montedoro F. 2000. The phenolic and volatile compounds of virgin olive oil: relationship with the endogenous oxidoreductases during the mechanical oil extraction process. Flavour Frag. Chem. 17, 163-173.

Servili M, Selvaggini R, Taticchi A, Esposto S, Montedoro G. 2003a. Air exposure time of olive pastes during the extraction process and phenolic and volatile composition of virgin olive oil. J. Am. Oil Chem. Soc. 80, 685-695.

Servili M, Selvaggini R, Taticchi A, Esposto S, Montedoro G. 2003b. Volatile compounds and phenolic composition of virgin olive oil: optimization of temperature and time of exposure of olive pastes to air contact during the mechanical extraction process. J. Agric. Food Chem. 51, 27, 7980-7988.

Servili M, Taticchi A, Esposto S, Urbani S, Selvaggini R, Montedoro G. 2008. Influence of the decrease in oxygen during malaxation of olive paste on the composition of volatiles and phenolic compounds in virgin olive oil. J. Agric. Food Chem. 56, 10048-10055.

Taticchi A, Servili M, Esposto S, Urbani S, Selvaggini R, Montedoro G. 2007. A new approach to the malaxation management using head-space sensors in virgin olive oil production. Proceedings of the 3rd CIGR Section VI International Symposium on "Food and agricultural products: processing and innovations. Naples, Italy, 24-26 September.

Tunlasakun K, Kirtikara K, Thepa S, Monyakul V. 2004. A Microcontroller-Based Islanding Detection For Grid Connected Inverter. In The 47th Midwest Symposium on Circuits and Systems, 267-269.

Visioli F, Galli C, Galli G, Caruso D. 2002. Biological activities and metabolic fate of olive oil phenols. Eur. J. Lipid Sci. Tech. 104, 677-684.

Recibido: 8/5/12 Aceptado: 12/9/12 